\title{
CONFIGURAÇÕES DA FLLOSOFIA: O PERCURSO ESCOLAR NO ESTADO NOVO
}

\section{Luísa Nogueira}

Centro de Filosofia UL

Desconhecer o valor da teoria, a sua influência como principal diretriz de todo o ensino, mesmo do técnico, é desconhecer o mais fundamental da educação e da instrução. É desconhecer o valor da ciência.

VIEIRA DE AlmeIda, 1910

\section{Introdução}

Decorridos praticamente cem anos sobre estas afirmações de Vieira de Almeida, não receamos considerá-las como representativas de uma posição que permite equacionar corretamente os problemas em torno da educação, do ensino, da instituição escolar e daquilo que se deve constituir como ponto de partida e horizonte: a ciência. Por ciência entendemos, em sentido lato, todo o saber racional, organizado e sistematizado, todo o saber disciplinar com estatuto epistémico reconhecido na tradição do Ocidente. No entanto, o processo de constituição das disciplinas escolares, o percurso escolar dos saberes, no nosso caso, da filosofia, torna visível as dificuldades por que pode passar o seu ensino, os conflitos que atravessam o saber em contexto escolar e obscuros compromissos, nem sempre assumidos.

Neste artigo, apresentamos uma visão da filosofia e do seu ensino liceal, a partir da política escolar e educativa do Estado Novo (1933-1974). Ao mesmo tempo, pretendemos que esta breve viagem ao passado contribua também para pensar as tensões com que hoje a Escola se debate. Solicitada por intenções educativas que se expandem e alargam tentacularmente, desdobrada por múltiplos planos e atividades, pressionada pelo discurso da competitividade e do sucesso, a instituição escolar precisa de ter claro o espaço que deixa para o saber. 


\section{A Filosofia como disciplina escolar}

O nosso ponto de partida é a existência histórica e factual de uma disciplina escolar, de um saber escolar e ensinável organizado didaticamente segundo um programa, no âmbito de um currículo de estudos e de uma política educativa. Abordamos a filosofia tal como se foi constituindo como disciplina no espaço escolar não superior, nos Liceus, criados em Portugal, em 1836, por Passos Manuel. ${ }^{1}$

A produção filosófica pode, de algum modo, ser um trabalho solitário e pôr entre parênteses as questões que ao autor não interessarem, mas a transmissão do saber filosófico, no quadro de um sistema de ensino formal, exige que se relacione necessariamente com uma dimensão política, educativa e institucional. A condição de disciplina escolar supõe a ensinabilidade no quadro de um sistema de ensino e a transmissibilidade mediada por processos de didatização. Programas de ensino, integração em objetivos educativos, ensino através de livros escolares elaborados ou adotados para o efeito, por meio de determinadas práticas pedagógicas constituem elementos mediadores do saber filosófico que o configuram escolarmente.

As disciplinas escolares resultam, em parte, de um processo de compartimentação e segmentação do saber com vista a um determinado processo de transmissão escolar. Esta visão do saber em disciplinas está associada à formação da racionalidade moderna, a par da quebra da unidade do saber escolástico e da substituição dos Colégios Jesuítas pelas Escolas do Estado. É a partir da criação dos Liceus, nome prestigiante para referir o espaço próprio das aprendizagens do Ensino Secundário; a partir da organização de um currículo de estudos e não apenas de um plano, como acontece pela primeira vez em $1880 ; 2$ a partir do aparecimento de programas de ensino e de um sistema organizacional de ensino, racionalizado, burocratizado e estatal ao longo do século XIX; a partir destes fatores é que poderemos, com rigor, considerar a existência de "disciplinas escolares". ${ }^{3}$ No entanto, o lugar da filosofia, da aula de filosofia, no quadro de estudos que mais tarde se veio a denominar de nível secundário, data das Reformas Pombalinas de 1759 (Alvará de 28 de junho) e de 1772 (Alvará de 12 de novembro). Desde então, a situação escolar da filosofia no ensino médio (carga letiva, programa, manuais...) tem

' Reforma da Instrução Secundária de Passos Manuel, Decreto de 17 de novembro de 1836.

${ }^{2}$ Reforma da Instrução Pública de José Luciano de Castro, Carta de Lei de 14 de junho de 1880.

${ }^{3}$ Sobre a história do termo "disciplina" e a constituição das "disciplinas escolares" veja-se André Chervel, "Historia de las disciplinas escolares. Reflexiones sobre un campo de investigación”, Revista de Educación, 295 (1991), pp. 59-112. 
sido permeável às vicissitudes do campo político (de que a política escolar e educativa é uma parte) e às características do espaço cultural que, aliás, o pensamento filosófico partilha. Neste sentido, podemos falar da existência de uma tradição escolar de ensino da filosofia. Razões internas ou razões externas à filosofia justificarão oscilações do seu estatuto curricular, determinadas orientações dos programas, predomínio de objetivos educativos ou a dominância de certos manuais. O prestígio académico da disciplina de filosofia (forte ou fraco) e as mudanças no plano dos seus conteúdos programáticos não estão dissociados nem da sua situação epistémica e das suas relações com outros saberes, nem das funções atribuídas à Escola e ao Ensino Secundário, ou do desenvolvimento da Pedagogia, da Didática e da política geral, escolar e educativa.

De que filosofia falamos quando nos referimos à filosofia ensinada nas escolas? Existe um processo de reconfiguração dos saberes para efeitos de ensino que implica interferências de fatores de diversa ordem, nomeadamente, de política educativa, de pedagogia e didática geral, de psicologia da aprendizagem. A interferência destes fatores é normalmente condição para a existência de uma disciplina escolar, mas é preciso garantir um equilíbrio no modo como se relacionam entre si e com o campo de saber ao qual se referenciam. ${ }^{4}$ Assim, por exemplo, nenhum procedimento didático se pode constituir como uma forma vazia de aplicabilidade universal e todo o ensino é primeiramente ensino de. Isto significa, quanto a nós, a indispensabilidade de cada campo de saber que tem a sua representação escolar participar ativamente no processo de reconfiguração que transforma uma ciência (na aceção original de um conjunto organizado e sistemático de conhecimentos) numa disciplina escolar. Se bem que as disciplinas escolares não possam ser consideradas simplesmente como tradução curricular direta das epistemai, nas disciplinas que podemos considerar tradicionais e que se mantêm com essa designação, como a matemática, a física ou a filosofia, por exemplo, há uma relação entre o campo curricular e pedagógico-didático e o campo da atividade de investigação que deve ser pensada. Como é que determinado campo de saber em contexto de ensino e de

\footnotetext{
${ }^{4}$ Sobre o problema da constituição e estatuto do saber escolar, remetemos para os estudos de Yves Chevallard (La transposition didactique. Grenoble: La pensée sauvage, 1991) e de André Chervel (La culture scolaire - un approche historique. Paris: Belin, 1998). Para o primeiro deve estabelecer-se uma diferença entre o saber, a ciência, e o saber ensinado, o saber escolar, que ocorre pelos processos de transposição didática. Nesta perspetiva, o saber escolar (savoir enseigné) mantém como referência fundamental o saber de origem do qual toma o nome (savoir savant). A escola é concebida fundamentalmente como lugar de transmissão de saber. Para Chevrel, a história da constituição das disciplinas escolares mostra que há um saber escolar, socialmente construído, que não pode ser perspetivado como simples transposição curricular das epistemai. A instituição escolar, neste sentido, é também produtora de saber.
} 
aprendizagem se relaciona com o saber que representa, quer dizer, com o seu campo produtivo e investigativo? Como é que, por exemplo, a história que se ensina se relaciona com a história que investiga e que produz conhecimentos? $\mathrm{Ou}$, como é que a física que se constitui como objeto de ensino se relaciona com a ciência física, a ciência que se pratica e que inova? Ou, como é que a filosofia que se ensina se relaciona com o saber filosófico? A questão é dupla:

1) A de saber até que ponto o ensino deve, ou pode, aproximar-se, de um ponto de vista processual e metodológico, dos processos que estão na base da constituição epistémica de determinado campo de saber.

2) A de interrogar acerca do critério de seleção dos conteúdos escolares para um programa que supõe um determinado contexto de ensino (grau, classe etária, curso...).

Admitindo, com Hegel, "que o conteúdo objetivo do que se aprende na escola é algo já pronto há muito tempo", 5 podemos perguntar até que ponto pertence à natureza do ensino escolar o ser compendiário, condensado e abreviado, sistematizado segundo uma ordem de ensino e de transmissão que, assim, se opõe à ordem da descoberta.

É possível conceber o ensino de uma ciência, como a física por exemplo, sem o recurso a procedimentos experimentais ou aceitar um ensino da filosofia que não seja filosófico? Segundo que critério se determina o "filosófico"? Estas são, no entanto, questões que só podem ser respondidas por cada campo disciplinar e, aparentemente, em nada se misturam com questões de política escolar ou de controlo político-ideológico sobre os conhecimentos ensináveis, o que nos conduz à segunda questão relativa ao seu critério de seleção. No entanto, particularmente no período do Estado Novo, o ensino e os processos de compendiação do saber no âmbito de um sistema de ensino público estatal, de âmbito nacional e com finalidades educativas definidas por uma orientação geral de política escolar, fazem com que o ensino na escola e a compendiação do saber se torne dominantemente, para além de uma questão científico-pedagógica e didática, uma questão política e ideológica. Este acontecimento, não sendo novo, adquire uma dimensão, pela consistência e durabilidade, que deixou marcas na representação escolar do saber filosófico. $\mathrm{O}$ início deste processo que irá permitir confundir o discurso filosófico com um discurso ideológico ou meramente edificante far-se-á a coberto de intencionalidades educativas e formativas tomadas como prioridade no sistema escolar.

${ }^{5}$ Hegel, Discursos sobre educação, tradução e apresentação de Ermelinda Fernandes. Lisboa: Colibri, 1994, p. 64. 


\section{O predomínio da educação no sistema escolar}

“O Ministério da Instrução Pública passa a denominar-se da Educação Nacional". ${ }^{6}$ É este o conteúdo da Base I da primeira Lei de Bases da Educação do século XX. Estamos em 1936, no início do Estado Novo e está criado, através deste ato legislativo, o Ministério da Educação Nacional, responsável pela administração escolar, por todos os assuntos relativos ao sistema de ensino, pela aplicação da política educativa do governo. A alteração do nome do Ministério, em 1936, acabará por traduzir a prática de intervenção dos ministros da Ditadura em prol da Educação, ao mesmo tempo que a institui como programa futuro de ação. Esta nova designação não é, por isso, neutra. Pelo contrário, condensa a linha de ação educativa do Estado Novo em dois aspetos fundamentais:

1) O predomínio da "educação" sobre a "instrução";

2) O desígnio da "nacionalidade" no âmbito das políticas de ensino.

Para compreendermos o significado e o alcance de uma opção de política escolar pela "educação", é importante compreender o modo como foi sendo realizada a estabilização semântica dos termos "instrução" e "educação", nos documentos legislativos e no discurso pedagógico, e como foram estabelecidas as suas relações. Tanto quanto a distinção semântica entre os termos instruir e educar, interessa-nos verificar o modo como o termo educação, para além de centrado nos aspetos morais, de formação do caráter e de formação cívica e política, se vai afastando da instrução. É principalmente este processo de divergência que cria condições para que o "educativo" tenda a justificar-se autonomamente no âmbito do sistema de ensino e, no limite, tenda a submeter o saber (o instrutivo) a critérios de índole educativa política e ideologicamente definidos. Trata-se de mostrar e compreender como se torna possível, no âmbito da educação institucional e do sistema de ensino, que o critério político-ideológico prepondere sobre o científico-pedagógico. Operamos aqui uma distinção entre o plano simplesmente "político" e o plano "político-ideológico". Consideramos o conceito de "político" em duas aceções fundamentais:

1) Sistema de poder organizado que decide sobre os principais aspetos da vida social de um país ou de uma nação (economia, defesa, justiça, educação...).

2) Esfera de vida comum partilhada pela pluralidade dos homens.

\footnotetext{
${ }^{6}$ Lei n. ${ }^{\circ} 1941$, de 16 de abril de 1936, Base I. Embora, após a Revolução de 25 de abril de 1974 , nunca mais tenha aparecido o termo "educação nacional", o termo "educação", apesar de integrado numa grande diversidade de designações, nunca mais desapareceu do Ministério encarregue das questões do ensino.
} 
A política como sistema organizado do poder está fundada no facto de os homens se agruparem em sociedade, de viverem em conjunto e de criarem um mundo comum pela sua ação. ${ }^{7}$

O "político-ideológico" refere-se:

1) A um sistema de ideias, hábitos e crenças associados, de forma deliberada ou não, a uma estratégia de reforço e manutenção de uma determinada forma de poder. Esta estratégia concorre para a perpetuação de determinadas formas de dominação e de submissão numa dada estrutura político-social e tem como condição de funcionamento e de êxito a ocultação, de diversos modos, das verdadeiras relações de poder. A "ideologia", neste contexto, funciona para além de elemento de coesão e conservação sociais, como fator de legitimação e perpetuação de uma determinada ordem social e de um determinado sistema político. Neste sentido, qualquer sistema político será ideológico na medida em que todo o poder tende à sua autopreservação, através de um sistema de ideias que o legitima e justifica.

2) A um dispositivo do poder para se afirmar politicamente como única força operante no espaço público, o que significa a anulação deste enquanto espaço de debate, discussão e exercício da cidadania. Neste sentido, o político-ideológico significa a redução do "político" ao domínio, ao exercício da autoridade e a eliminação do espaço público enquanto espaço político comum. Em seu lugar, desenvolve-se um sistema de doutrinação, acompanhado por propaganda e encenação, que se dissemina pelas instituições, pela sociedade. A "ideologia" corresponde a um processo de construção simbólica de imagens do sujeito e do real de forma a impedir o exercício da crítica e da recriação do real pela utopia. É uma estratégia ativa e deliberada de atribuição de sentido à experiência comum que se pretende única e "verdadeira".

Esta elucidação semântica dos termos "político(a)" e político-ideológico permite que os utilizemos sem ambiguidade. Assim, se a educação, no âmbito do sistema de ensino, é sempre resultado de uma política global de que a política educativa é parte, isso não implica que essa mesma educação

\footnotetext{
${ }^{7}$ Seguimos o pensamento de Hannah Arendt ao afirmar: "A ação, a única atividade que se exerce diretamente entre os homens sem a mediação das coisas ou da matéria, corresponde à condição humana da pluralidade, ao facto de que homens, e não o Homem, vivem na Terra e habitam o mundo. Todos os aspetos da condição humana têm alguma relação com a politica; mas esta pluralidade é especificamente a condição - não apenas a conditio sine qua non - mas a conditio per quam - de toda a vida política". Hannah Arendt, A Condição Humana. Lisboa: Relógio d'Água, 2001, p. 20.
} 
seja orientada segundo critérios político-ideológicos. A dimensão política do ato educativo não tem de se confundir com processos de doutrinação político-ideológica. É possível conciliar política e educação, educação e ensino, política e liberdade. No Estado Novo, sob um regime político autoritário, o domínio sobre as escolas exercia-se através da legislação de ensino, do controle ideológico sobre os compêndios e de um conjunto de programas de ação visando intervir na formação da consciência e da personalidade individual.

Durante dez anos, de 1926 a 1936, data da primeira grande reforma do ensino liceal do Estado Novo, à medida que se vai estabilizando um sistema político que consuma a revolução "anti-liberal", "anti-democrática", "anti-plutocrática" e "autoritária", nas palavras de João Ameal, ${ }^{8}$ assistimos a um conjunto de medidas legislativas respeitantes ao Ensino Secundário, orientadas negativamente pelo ataque ao "enciclopedismo" da República, ao excesso informativo e, positivamente, pela construção de um sistema de ensino com dominância dos aspetos educativos.

O período que se inicia com o golpe de Estado de 1926 e que vai até a promulgação da Constituição de 1933, denominado "Ditadura Nacional", mais do que a distinção entre instrução e educação, entre os aspetos informativos do ensino e os aspetos formativos, acentua uma dicotomia. ${ }^{9}$ É o estabelecimento dessa dicotomia que irá, por sua vez, permitir o estabelecimento de uma relação hierárquica entre formação e informação, em que a primeira domina a segunda, até o ponto limite da possibilidade de uma completa separação entre elas. Esta separação semântica cria a possibilidade de esses termos serem enunciados separadamente, e de se colocar a ênfase, sistematicamente, na vertente educativa, pela escolha reiterada dos termos "formação" e "educação" nos documentos e nos discursos oficiais sobre educação. ${ }^{10}$

A educação, por sua vez, define-se como educação moral, a moral como moral cristã, segundo um critério político estatal normalizador. Os campos da moral e da religião tendem a confundir-se, ao mesmo tempo que a formação religiosa se especifica como cristã.

\footnotetext{
${ }^{8}$ João Ameal, Construção do Novo Estado. Porto: Livraria Tavares Martins, 1938, pp. 12-16.

${ }^{9}$ O período que vai de 1926 a 1933 é considerado como um período de transição e marcado por conflitualidades. $C f$. S. Stoer e Helena Araújo, "A contribuição da educação para a formação do Estado Novo: continuidades e ruturas, 1926-1933”. In: O Estado Novo, das origens ao fim da autarcia (1926-1959). Lisboa: Fragmentos, 1987, vol. II, p. 133.

${ }^{10}$ Adotamos a definição de Olivier Reoul de discurso oficial como sendo "o dos homens que têm o poder de definir a pedagogia ou de a modificar na sua organização, nos seus conteúdos, nos seus métodos. Discursos de ministros e dos seus representantes. Discurso dos organismos internacionais, cujo poder é função dos créditos que podem dispensar. Discurso enfim de certos manuais ou dicionários 'consagrados"'. Olivier Reboul, Le langage de l'éducation. Paris: PUF, 1984, p. 43.
} 
A Constituição de 1933 tinha considerado o ensino "independente de qualquer culto religioso", se bem "que não o devesse hostilizar"; a revisão da Constituição, em 1935, considerava os objetivos e a orientação do ensino segundo os "princípios da doutrina e moral cristãs, tradicionais do País", subentendendo-se que se tratava da moral cristã católica. Em plena década de cinquenta, o texto constitucional irá mais longe e a religião católica será considerada a "religião da Nação portuguesa". " Em 1964, dez anos antes da queda do regime, o Ministro da Educação considerará a necessidade de um estatuto da Educação Nacional:

[...] onde se dê forma e expressão a um sistema renovado da ação educativa, fiel às grandes constantes do cristianismo e da lusitanidade, mas modernizado em função das exigências do presente e das tendências do porvir. ${ }^{12}$

Também a Junta de Educação Nacional, órgão consultivo do Ministério da Educação desde a sua criação em 1936, na sua remodelação de 1965 , "tornou possível, pela primeira vez a representação da Igreja e do ensino particular em órgãos do Ministério da Educação Nacional". ${ }^{13}$

\section{Educação e ensino}

O enunciar do aspeto educativo como mais-valia da Escola tende a distinguir e separar: os saberes e a formação do carácter; o conhecimento e a moral; a instrução e a educação. A possibilidade de submissão da vertente intelectual e informativa do ensino (os saberes, o conhecimento, a instrução) à vertente educativa será consequência natural desta distinção e separação, feitas à custa de uma abstração simplificadora. O educativo é reduzido ao moral e, com esta redução, impede-se que o problema das relações entre instrução e educação seja colocado na sua complexidade e dinamismo. A separação em dois campos semânticos acantona o saber e o conhecimento no campo do instrutivo e dis-

11 "É livre o culto público ou particular da religião católica como religião da Nação Portuguesa [...]", artigo $45 .^{\circ}$ da Constituição da República Portuguesa, com as alterações da revisão constitucional pela Lei n. ${ }^{\circ} 2100$, publicada no Diário do Governo, n. ${ }^{\circ} 198,1$. $^{a}$ série, de 29 de agosto de 1959.

12 Discurso do Ministro da Educação Galvão Teles (sublinhados nossos), apud Rui Grácio, "O Sistema Escolar Metropolitano - Portugal, 1970". In: Obra Completa. Lisboa: Fundação Calouste Gulbenkian, 1995, vol. II, p. 208. Em 1959, o ministro da Educação Francisco Leite Pinto tinha solicitado à OECE (a OCDE sucede-lhe em 1960) a realização de um diagnóstico sobre as necessidades educativas em Portugal, o que deu origem ao Projeto Regional do Mediterrâneo que abrangeu a Espanha, Grécia, Itália, Jugoslávia e Turquia). Cf. Ibid., p. 218.

${ }^{13}$ Rui Grácio, ob. cit., p. 203. 
ponibiliza-o como realidade instrumental. $O$ saber e o conhecimento passam a ser olhados do exterior, como um conjunto de resultados, que devem ou não ser ensinados, e a questão do ensino escolar, antes de ser didática e pedagógica, é social e política. ${ }^{14}$

A distinção entre o instrutivo e o educativo, com a finalidade de conferir supremacia ao educativo, acaba por conduzir, num segundo momento, para a absorção do instrutivo pelo campo educativo. $O$ educativo pode assumir a hegemonia no espaço da escola sob formas de mera doutrinação e inculcação ideológica, na medida em que se perde a ligação da educação ao saber e à ciência concebidos como espaço de investigação autónomos. Estamos longe de considerar simplesmente que o desenvolvimento moral dos alunos deva ser um dos efeitos do ensino dos liceus, como considerava a legislação de ensino da Reforma de 1894-1895 e toda a legislação publicada durante a I República referente ao ensino secundário:

O desenvolvimento moral dos alunos deve ser um dos efeitos do ensino dos liceus. O exercício oferecido pelos estudos secundários; a atenção e o zelo que o trabalho nas aulas exige; a pontualidade e exatidão no cumprimento dos numerosos deveres escolares; e com especialidade o conteúdo ético das lições nas diferentes matérias, são meios eficazes que encaminharão àquele desenvolvimento. $^{15}$

Dir-se-á que na I República, no ensino secundário, só o conhecimento, o saber, podiam ser objeto de ensino e constituírem-se na forma de disciplinas escolares. Sendo assim, seria natural que, nos graus de ensino mais avançados, em que são maiores as exigências intelectuais e a complexidade das matérias, a instrução cívica fosse dada durante o ensino de certas disciplinas e que fosse "ministrada", nomeadamente, através das "associações escolares dirigidas pelos alunos", ou por "comemorações de datas históricas nacionais", ou pela "organização disciplinar das classes e turmas liceais em que os alunos poderão

${ }^{14}$ Em 1935, o Decreto-lei n. ${ }^{\circ} 25447$, que regulamenta o processo de aprovação de livros escolares, considera no preâmbulo justificativo: "[...] não pode o Governo abstrair da orientação social e política das escolas no sentido e avigoramento de uma mentalidade nacionalista, que dê garantias seguras de que o esforço despendido pela Revolução Nacional de 28 de Maio seja convenientemente aproveitado a bem da Nação".

${ }^{15}$ O texto continua: "Sua prática é, de conseguinte, utilíssima; e por isso toda a corporação dos liceus se empenhará em mantê-la, tendo muito em vista que lhe incumbe corresponder de maneira completa, também neste ponto, não só nos assuntos literários, à responsabilidade pública em que se acha investida, responsabilidade que é uma das prerrogativas do magistério do Estado", cap. III - Do ensino, artigo $22 .^{\circ}$, n. $^{\circ} 12 .^{\circ}$, Decreto de 14 de agosto de 1895 (cf. cap. VII - Da orientação do ensino, artigo $125^{\circ}, \mathrm{n} .^{\circ} 13^{\circ}$, no Decreto n..$^{\circ} 4799$, de 12 de setembro de 1918). A legislação de 1905 remete para o Decreto de 14 de agosto de 1895 , transcrevendo em nota este artigo 22 . $^{\circ}$ sob a designação de "indicações pedagógicas". 
praticar a vida social'. ${ }^{16}$ A instrução ou educação moral e cívica não constituíam propriamente o que se designa como disciplina escolar. Aquela responde à necessidade de uma educação política com vista ao exercício da cidadania, cuja responsabilidade incumbe à Escola, mas a moral, o civismo ou a política não pertencem ao campo epistemológico do saber ou da ciência. A este respeito, é também significativa a posição, expressa em 1913, pela "Comissão do projeto de reforma do ensino secundário", ${ }^{17}$ sob presidência de Adolfo Coelho, ao considerar que "em toda a vida liceal estão imanentes os elementos da educação moral e cívica pelo hábito" e que, "nas disciplinas dos dois cursos, especialmente nas ciências do espírito, os meios da educação moral e cívica" se fazem "pelas ideias, sem inscrições especiais no programa" ${ }^{18}$ (sublinhado nosso). A educação liceal visa a "construção do homem completo", incluindo o saber, o ser e o fazer, ultrapassando a "falsa distinção entre educação e ensino, entre ensino teórico e utilitário". No entanto, a necessidade de fazer referência à educação científica que deve dominar o ensino liceal, a propósito do ensino da história, parece revelar uma situação perigosa:

A história não pode excluir-se da regra que deve dominar o ensino secundário de que este dá educação não só estética e moral, mas também científica $[\ldots]{ }^{19}$

Podemos dizer que as dificuldades em distinguir a educação moral e a educação científica, em clarificar a dimensão formativa do ensino e em clarificar as funções atribuídas à escola teriam conduzido, ao longo do Estado Novo, a uma valorização escolar e curricular de crenças, convicções e valores. O que se admitirá no Estado Novo, mesmo que de forma não tematizada, é que a educação não deixando de ser uma prática, possa ser objeto formal de ensino, admitindo-se a possibilidade de ensinar o que não se constitui nem como ciência ou saber, nem como técnica. Na estrutura curricular do Ensino Secundário, as crenças, as convicções (políticas ou religiosas) podem ser ensinadas e organizam-se curricularmente em "sessões", aproximando-se das disciplinas escolares que são determinadas fundamentalmente a partir dos campos epistémicos constituídos. Não se trata simplesmente de aproveitar "o potencial normativo das disciplinas", como se dizia em 1918 no texto preambular aos programas da instrução secundária, mas de o determinar previamente e de o constituir como campo disciplinar. A diferença pode parecer ténue, mas representa um ponto de vista distinto sobre o ensino, que inicia um processo de consequências significativas no ensino e na investigação. Consideramos que estamos perante

\footnotetext{
${ }^{16}$ Idem, artigo $188 .^{\circ}$.

17 "Comissão de projeto da reforma do ensino secundário", Diário do Governo, n. 127 , de 2 de junho de 1913 (publicado ainda sob responsabilidade do Ministério do Interior).

${ }^{18}$ Ibid. (sublinhado nosso).

${ }^{19} \mathrm{Ibid}$. (sublinhado nosso).
} 
um deslize que opera uma transição flutuante entre o campo educativo, concebido como prática vivida e exemplar, e o campo curricular, como teoria ensinável. A nosso ver, isso significa o progressivo enfraquecimento das condições de cientificidade do saber ensinável e das relações entre cientificidade e ensinabilidade, das quais resulta toda a riqueza e complexidade da reflexão pedagógica e didática. De consequência, o desenvolvimento moral passa a ser princípio, de efeito do ensino, sua causa. É uma inversão decisiva. A razão de ser do ensino é agora a educação, de modo que o sistema escolar deve concentrar em si a tarefa educativa. Ensinar confunde-se com educar. Sendo o aspeto educativo entendido como uma dimensão exterior ao saber, definido mediante critérios meramente politico-ideológicos, corre-se também o risco de lhes subordinar o material informativo e de abrir portas a uma instrumentalização do conhecimento. Diferentemente, concebendo o educativo não como um aspeto exterior a determinado saber, mas como a exploração das suas virtualidades, a determinação dos conteúdos ensináveis seria sempre uma questão de critério pedagógico e didático da responsabilidade de cada campo disciplinar. No primeiro caso, a seleção do que nele deve ser ensinável é feita a partir de uma intencionalidade educativa definida segundo critérios exteriores aos campos disciplinares. No segundo caso, a exploração da dimensão educativa é determinada mediante critérios intrínsecos ao próprio saber. A questão da determinação dos saberes ensináveis do currículo escolar não pode ser resumida a este esquema, mas ele representa uma primeira abordagem que nos ajuda a analisar uma posição teórica que, distinguindo instrução e educação numa linha de aparente continuidade com a prática escolar da I República, revela uma diferente perspetiva e atitude relativamente à educação, ao ensino e aos agentes educativos, de pesadas consequências. Uma atitude que coloca a dimensão educativa acima da informativa, por exemplo, tenderá a desculpar, se for caso disso, fraquezas científicas por tendências ideológicas ou qualidades de carácter, ou a sacrificar qualidade científica a tendências ideológicas ou de caráter. Isto significa, no limite, que os critérios de ordem moral e política poderão prevalecer sobre o critério científico ou pedagógico. Efetivamente, é o que veremos acontecer ao longo do Estado Novo, com o processo de seleção e classificação dos professores ou com o afastamento de professores do exercício da docência por motivos políticos, extrínsecos à sua qualidade científica ou pedagógica. A denominada "idoneidade" moral dos professores, que se refere à sua conduta do ponto de vista cívico, político e de prática de culto (cristão e católico), virá a ser condição de ingresso na carreira docente, tal como será fator suficiente para a impossibilidade do seu exercício. ${ }^{20}$ Sob esta expressão caberá o controlo de aspetos do comporta-

${ }^{20}$ Lembremo-nos, por exemplo, que as qualificações para o ensino primário eram mínimas; aceitavam-se pessoas sem formação científica mas que possuíam "idoneidade moral". 
mento político e público ou da vida pessoal e privada, ${ }^{21}$ bem como a ativação de mecanismos de punição perante o que pudesse ser considerado moralmente censurável. Corria já o ano de 1944, por exemplo, quando Joaquim de Carvalho, Professor na Universidade de Coimbra, foi "encarregado pelo Governo de proceder a uma sindicância a um professor de Liceu que, à passagem de uma procissão do Corpo de Deus, se não levantara do banco ao lado nem se descobrira, tendo acabado por fazê-lo, a uma intimação de um polícia". ${ }^{22}$

Rómulo de Carvalho, na sua História do Ensino em Portugal refere, a propósito do ensino primário e da criação de "postos de ensino" e dos "regentes escolares", em 1931, que se admitiam "pessoas a quem não se exigiria qualquer habilitação mas apenas a comprovação de possuírem a 'necessária idoneidade moral e intelectual' e que "os abusos cometidos foram de tal ordem que, cerca de quatro anos depois, já na impossibilidade de se esconder o que estava acontecendo, foi necessário publicar um novo decreto, com data de 28 de agosto de 1935, para se passar a exigir um exame de aptidão". Em nota de rodapé, dá conta de uma situação caricata de que teve conhecimento por "informação privada de um alto funcionário da Instrução, de que um pretendente a regente escolar declarara, ao ter que assinar o auto de posse, que não sabia escrever". Rómulo de Carvalho, História do Ensino em Portugal, desde a fundação da nacionalidade até ao fim do regime de Salazar-Caetano. Lisboa: Fundação Calouste Gulbenkian, 2001, p. 736. O critério da "idoneidade" será também aplicado aos candidatos à docência em Canto Coral ou Organização Política e Administrativa da Nação. Como se lê no Decreto n. ${ }^{\circ} 27$ 085, de 14 de outubro de 1936, artigo 23.,$\S 7 .^{\circ}$ : "Para o ensino de educação moral e cívica, de educação física, de canto coral e de lavores femininos pode ser autorizado o contrato de indivíduos que, embora não possuam as habilitações normais, sejam julgados idóneos em despacho ministerial, sobre parecer da Junta Nacional de Educação, enquanto não for reorganizado o regime legal da respetiva formação pedagógica"; e no $\S 8$. : "São de livre nomeação do Ministro os professores da disciplina de organização politica e administrativa da Nação, de entre os diplomados com um curso superior e outros indivíduos de idoneidade reconhecida, sobre parecer da Junta Nacional de Educação [...]". Em 1947, o Decreto n. ${ }^{\circ} 36507$, de 17 de setembro, no artigo $17 .^{\circ}$, determina: "O ensino liceal só poderá ser ministrado pelos indivíduos em quem o Estado reconheça, além da natural competência científica e pedagógica, a indispensável idoneidade moral e civica" (sublinhados nossos).

${ }^{21}$ O casamento das professoras primárias e das enfermeiras será, por exemplo, objeto de legislação especifica.

22 Joaquim de Carvalho, "Carta a Carlos Alberto da Costa Soares". Obra Completa, Ensaios e Fragmentos filosóficos e bibliográficos. Lisboa: Fundação Calouste Gulbenkian, 1996, vol. VIII, p. 149. A resposta dada por Joaquim de Carvalho, após insistência com uma segunda carta do Delegado do Procurador Geral da República em Oliveira de Frades, Carlos Alberto da Costa Soares, inclui uma primeira análise, "geral in abstrato", segundo a qual "o ato deste professor é censurável moralmente" e acaba distinguindo censura moral e punição através da pergunta "Será, porém, além de censurável, punível?". Num segundo momento, numa análise "em concreto" Joaquim de Carvalho, não tendo "conhecimento da pessoa e das circunstâncias do ato cometido" afirma que, "em rigor não posso julgar, mas apenas ponderar". É claro o incómodo desta situação para Joaquim de Carvalho que, depois de incluir elementos de ponderação, como a de que o ato do professor poderia estar ligado a uma atitude anti-clerical mas não anti-religiosa, o que seria fator atenuante, conclui de forma cautelosa mas sem ambiguidade: "Atrevo-me, porém, a pensar, em face da inquietação moral que a sociedade portuguesa padece nos nossos dias, e considerando que se tem levado, por vezes muito longe, o abafamento e sequestro das opiniões dissidentes - que são também uma condição 
Em 1935 é publicado o Decreto n..$^{\circ} 25$ 317, que impõe a aposentação, reforma ou demissão a quem não der "garantias de cooperação na realização dos fins superiores do Estado". Nesse mesmo ano, ao abrigo deste decreto, será afastado da docência Sílvio Lima, da Universidade de Coimbra, ${ }^{23}$ dos primeiros a sofrer o afastamento da carreira do ensino e da investigação. Outros se lhe seguirão num processo que descapitalizará o país dos seus quadros mais ricos e promissores (cujas consequências são visíveis na fraca produção científica portuguesa neste período). Nesse mesmo ano de 1935, são demitidos, com Sílvio Lima, o médico e homem de cultura Abel Salazar (Faculdade de Medicina da Universidade do Porto), o filólogo Rodrigues Lapa (Faculdade de Letras da Universidade de Lisboa), o cientista Aurélio Quintanilha (Faculdade de Ciências da Universidade de Coimbra). A mesma situação terá ocorrido com Agostinho da Silva, então professor liceal ${ }^{24}$ ou, embora sob contornos diferentes, com António Marinho. ${ }^{25}$ Já na década de quarenta, em 1944, o filósofo e historiador Vitorino Magalhães Godinho (Faculdade de Letras de Lisboa) e, já depois do final da II Grande Guerra, em 1946, o matemático Bento de Jesus Caraça (Instituto Superior de Ciências Económicas e Financeiras), o médico Francisco Pulido Valente (Faculdade de Medicina da Universidade de Lisboa), o físico Manuel Valadares (Laboratório de Física da Faculdade de Ciências da Universidade de Lisboa). ${ }^{26} \mathrm{~A}$ impossibilidade de interferir nos programas e nos livros de estudo a nível do ensino universitário, como se

necessária de uma sociedade civilizada - que são de admitir circunstâncias atenuantes. A repreensão, dando ensejo público à afirmação dos direitos e dos deveres da consciência religiosa seja qual for, talvez fosse socialmente mais eficiente que outra penalidade, e, além disto, mais caritativa e humana". Ibid., p. 149 (sublinhados nossos).

${ }^{23}$ Sílvio Lima era, na altura, professor de Psicologia Experimental e de Psicologia Escolar $e$ Medidas Mentais na Universidade de Coimbra. Será reintegrado "como professor extraordinário da 3." secção (Ciências Pedagógicas), em Janeiro de 1942" (Joaquim Ferreira Gomes, Para a História da Educação em Portugal. Porto: Porto Editora, 1995, p. 100). Para além de Sílvio Lima são demitidos, também neste ano, ao abrigo deste decreto, Abel Salazar, da Faculdade de Medicina da Universidade do Porto; Rodrigues Lapa, da Faculdade de Letras da Universidade de Lisboa; Aurélio Quintanilha, da Faculdade de Ciências da Universidade de Coimbra. $C f$. Alberto Amaral, recensão ao livro de Luís Reis Torgal, $A$ Universidade e o Estado Novo: o caso de Coimbra, 1926-1961. Coimbra: Minerva, 1999, em Análise Social, XXXV(154-155) (2000), p. 438.

${ }^{24}$ Cf. Miguel Real, Agostinho da Silva e a Cultura Portuguesa. Lisboa: Quidnovi, 2007, p. 18.

25 "Em 1937, e por ter protestado pela inclusão do seu nome sem seu consentimento num telegrama de repúdio pelo atentado anarquista ao Presidente do Conselho de Ministros, Marinho foi preso por alguns meses no Aljube, sendo-Ihe retirada, após libertação, a licença de ensino". Jorge Croce Rivera, “«Estádios no caminho da Verdade»: o percurso ético-metafisico de José Marinho". In: Pedro Calafate (Dir.), História do Pensamento Filosófico Português, vol. V, tomo 1, p. 217.

${ }^{26}$ Cf. Norberto Cunha, "A Declaração Universal dos Direitos do Homem (Luzes e sombras da sua receção em Portugal, em 1948)". Philosophica, 12 (1998), p. 20. 
estava a fazer em todos os outros graus de ensino, parece ter levado a uma atitude radical de afastamento de professores, com consequências gravosas para a qualidade do ensino superior e para a investigação científica em Portugal. O impedimento de ensinar na Universidade ou no ensino público teria trazido, no entanto, alguns benefícios para a qualidade do ensino liceal particular. A maioria dos professores impedidos de lecionar no ensino público, e que não se ausentavam do país, transitavam para os colégios particulares, o que constituía fator de enriquecimento da qualidade de ensino. $O$ facto de o ensino liceal ocupar um lugar intermédio na estrutura organizacional e administrativa do ensino fá-lo ter um estatuto de relativa autonomia relativamente ao sistema de pressão político-ideológico. Sem o poder da Universidade e sem a premência da formação ideológica da Escola Primária, pode escapar, em parte, à purga que se exerceu sobre o corpo docente das universidades ou, apesar de tudo, ao intenso controlo sobre os programas e conteúdos de ensino nos anos da escolaridade primária, apesar da imposição legal de um livro único para algumas disciplinas do ensino liceal: educação moral e cívica, história e filosofia. ${ }^{27}$ Ao mesmo tempo, a existência de uma cultura profissional pautada por graus altos de exigência científica e pedagógica terá permitido a manutenção de padrões de qualidade do ensino liceal.

\section{O enfraquecimento do espaço público e a defesa de uma "verdade nacional"}

Durante o período do Estado Novo, a moralidade, de que se dispensa o adjetivo cristã ou católica, transforma-se em superior princípio de espiritualidade que penetra todas as instâncias da vida da Nação e na qual se subsumem todos os diferentes aspetos da educação escolar. A moralidade constitui a face prática e visível de uma identidade individual e coletiva, de um "ser português" que inclui o ser cristão. Trata-se de uma inversão: o que até então pertencia à esfera privada do culto e da religião passa a estar subsumido na esfera da moralidade pública, passando até a justificar-se as intromissões na vida privada a partir de um critério exterior de moralidade. Também neste sentido a política do Estado se submete à moral religiosa e encontra aí um superior e transcendente critério de legitimação. Esta submissão da política a valores transcendentes, assumidos com pré-políticos ou meta-políticos, signi-

27 A determinação legal do livro único surge na legislação liceal de 1936: "Dentro de cada liceu será adotado um único livro para cada disciplina do mesmo ano, escolhido de entre os aprovados oficialmente, e serão comuns aos liceus de todo o Pais os compêndios de história, de filosofia e de educação moral e civica". Decreto n. 27 085, de 14 de outubro, artigo 32.", $\S 3 .^{\circ}$ (sublinhados nossos). 
fica precisamente a destruição da política entendida como atividade humana que decorre do encontro entre homens livres e iguais, significa que se retira do espaço público a discussão e o debate porque nada há para debater ou discutir. É o reino da "tirania da verdade", ${ }^{28}$ pois se a verdade eterna deve habitar a cidade, então os homens, na pluralidade e imperfeição das suas opiniões, não têm aí lugar. A tentativa de atribuir qualquer fundamento metafísico à política tem como consequência a destruição da política como espaço plural.

Reconduzida e reduzida a questão do ensino e do saber ensinável à questão mais vasta da construção de uma identidade nacional, é esta a medida do valor do saber, o seu critério último. Neste sentido, é natural que nenhum plano de estudos, nenhuma estrutura curricular, nenhum programa de ensino possa cumprir por completo a ação formativa e educativa do ensino secundário. As disciplinas curriculares fundamentam-se em saberes tradicionalmente constituídos, que sofreram um processo de didatização, e nem todas são permeáveis aos objetivos e finalidades últimas do sistema educativo. Daí o facto de, para além do controlo exercido através dos programas das disciplinas, das indicações relativas à sua orientação, dos manuais escolares, se tornar também necessário:

1) Criar uma disciplina para o último ciclo liceal, denominada organização política e administrativa da nação, para "conhecimento da estrutura orgânica do Estado e a formação da mentalidade corporativa". ${ }^{29}$

2) Determinar, como "adjuvantes do ensino e meios de ação educativa", "visitas de estudo e excursões", ${ }^{30}$ nas quais se aproveitarão todos os "ensejos para o conhecimento dos padrões da história pátria, como motivo de instrução geral e de educação moral e cívica" ${ }^{1}$ e "sessões culturais que visarão de modo particular o conhecimento do Império Colonial, a arte portuguesa e a educação cívica". 32

3) Determinar o carácter obrigatório das atividades da Mocidade Portuguesa para professores e alunos..$^{33}$

${ }^{28}$ Cf. Hannah Arendt, A Promessa da Politica. Lisboa: Relógio d'Água, 2007, p. 16

${ }^{29}$ Decreto $n .^{\circ} 27084$, de 14 de outubro de 1936, artigo $7^{\circ}, \S 2 .^{\circ}$.

${ }^{30}$ Ibid., artigo $100^{\circ}$.

${ }^{31}$ Ibid., $\S 2 .^{\circ}$

32 Ibid., artigo $11 .^{\circ}$.

33 "A organização nacional denominada Mocidade Portuguesa cooperará com todos os estabelecimentos oficiais e particulares do ensino liceal no que respeita ao desenvolvimento da capacidade física, à formação do carácter e à devoção à Pátria, no sentimento da ordem, no gosto da disciplina e no culto do dever militar". Ibid., artigo 3. . 
4) Relevar a importância das sessões do canto coral e da educação física para a formação moral e física dos portugueses e para os momentos de comemoração, exaltação e revitalização do sentimento coletivo da portugalidade.

A dominância da educação e a desvalorização da instrução, a aproximação entre o discurso pedagógico e o discurso político-ideológico liga-se a uma questão de fundo mais radical e própria: a tendência a esquecer a relação originária de todo o ensino ao saber. É que antes de ser ensino para..., todo o ensino é ensino de....A obnubilação deste aspeto, que é uma das mais fortes razões de toda a educação formal e fator essencial no sistema de ensino, é, quanto a nós, o que está na raiz da definição de um projeto de educação não apenas comprometido, mas subordinado nos seus princípios e na sua estrutura a um determinado projeto político-ideológico para o País. O que encontramos, em última análise, é uma determinada atitude face ao conhecimento e à verdade que os configuram no âmbito da esfera do político-ideológico. No limite, o critério de seleção curricular das matérias ensináveis será, assim, exterior aos campos disciplinares e aos critérios didático-pedagógico ou científico. Considerando a questão da educação como sendo eminentemente política, integrada a educação no grande projeto de restauração e ressurgimento nacional (apoiado em elementos de ordem metapolítica) vai-se perdendo a noção do vínculo essencial do ensino ao conhecimento e aparecem justificados um conjunto de atos perpetrados no periodo do Estado Novo. Pensemos, por exemplo, no desinvestimento na investigação psicopedagógica, em contraste com a riqueza do período da I República, ou na formação de professores. ${ }^{34}$ É assim que as questões da educação e do ensino tendem a perder a sua especificidade no campo que lhes é próprio, o da filosofia, da pedagogia ou mesmo das ciências da educação, podendo facilmente deslizar para o campo político-ideológico.

${ }^{34}$ O Decreto de 21 de maio de 1911 criava as Escolas Normais Stuperiores destinadas à formação de professores. Serão extintas pelo Decreto . $^{\circ} 18973$, de 16 de outubro de 1930 que cria a Secção de Ciências Pedagógicas nas Faculdades de Letras para ministrar a cultura pedagógica e determina que o estágio (de dois anos) seja feito nos Liceus Normais (Liceu Pedro Nunes, em Lisboa e Liceu Júlio Henriques, em Coimbra). Entre 1947 e 1956 será reduzido a um (em Coimbra). O Instituto Superior de Ciências Pedagógicas a que se faz referência no Decreto n. ${ }^{\circ} 36507$, de 17 de setembro de 1947, como a solução para o "problema da formação psicopedagógica dos professores" acaba por não ter passado de uma intenção anunciada (cf. Joaquim Ferreira Gomes, Para a História da Educação em Portugal. Seis estudos. Porto: Porto Editora, 1995, pp. 122-125). 
A história será a disciplina formativa por excelência, ${ }^{35}$ mas todas as disciplinas escolares devem, quer por via dos seus conteúdos programáticos específicos e dos seus objetivos cognitivos e educacionais, quer da ação educativa do professor, evidenciar a sua vertente formativa sob o ponto de vista moral, cívico, nacionalista e patriótico. Para além da história, o português ou a língua e a literatura portuguesa e, no terceiro ciclo ou no curso complementar, a filosofia, serão as disciplinas que evidenciam maior potencial formativo.

A afirmação constante na legislação de $1932,{ }^{36}$ ainda que referente ao ensino da história, mostra a intenção primeira de subordinação do ensinável e da ciência às linhas educativas politicamente definidas em função de valores metapolíticos e a legitimação de um critério político-estatal para a definição do ensinável:

[...] O Estado, sem se arrogar a posse exclusiva duma verdade absoluta, pode e deve definir a verdade nacional, quer dizer, a verdade que convém à Nação. ${ }^{37}$

Para poder sustentar a possibilidade desta "verdade nacional", desta "verdade que convém à Nação" vemos que o saber histórico é reduzido, para além dos "factos, datas, nomes", "inalteráveis", à completa subjetividade do historiador, "tal historiador, tal atitude". ${ }^{38}$ Assim, o que se põe em causa é o território especifico da ciência e das suas regras. Assistimos ao que denominamos conversão epistemológica da ciência em opinião e crença, com os seguintes argumentos:

1) $\mathrm{Na}$ "falta de um juiz infalível dessas atitudes que são meramente subjetivas", então o Estado deve intervir na definição da verdade nacional;

${ }^{35}$ A "história presta-se melhor do que qualquer outra disciplina, a cultivar o verdadeiro patriotismo, a dar excelentes lições de moral e a desenvolver o espírito cívico", lê-se no Decreto n. ${ }^{\circ} 16077$, de 26 de outubro de 1928. Embora a referência seja o ensino primário esta visão do papel da disciplina será mantida para os outros ciclos de ensino. $C f$. artigo de S. Stoer e Helena Araújo, "A contribuição da educação para a formação do Estado Novo: Continuidades e ruturas 1926-1933". In: O Estado Novo das origens ao fim da autarcia 1926-1959, vol. II, p. 137.

${ }^{36}$ Referimo-nos ao Decreto n..$^{\circ} 21$ 103, datado de 7 de abril e publicado a 15 de abril de 1932, que visava esclarecer os "pedidos de informação sobre o significado e a latitude da expressão 'exatidão nas doutrinas', inserta no artigo $13 .^{\circ}$ do Decreto n. ${ }^{\circ} 19605$, de 15 de abril de 1931 , quando de aplicar aos compêndios de História Pátria para o ensino secundário e do ensino técnico-profissional; [...]."

${ }^{37}$ Ibid.

${ }^{38}$ Ibid.. 
2) "Se os autores dos compêndios de história são os responsáveis pelos erros ou pelas verdades que defendem nos seus livros, o Estado é responsável pelo ensino que ministra nas suas escolas oficiais". ${ }^{39}$

Conseguida a mutação da ciência em opinião, torna-se possível outro movimento complementar:

1) O Estado, a opinião e a crença do Estado, estabelece-se como critério decisório do ensinável.

2) A ciência histórica passa a estar colocada no mesmo plano da política, o terreno da opinião por excelência, podendo, assim, estar sob o seu controlo.

"A opinião, coração da política, não tem relação com a verdade" 40 e, na mera luta entre opiniões, sem outro critério que não o dos interesses particulares em confronto, valerá a mais forte. Porque a reduziu a opinião sem relação com a razão crítica, o jogo político pode extravasar do campo social de atuação para o campo da constituição do Saber e da Ciência. Não estamos a falar de uma simples instrumentalização do Saber por parte do poder político-estatal, mas de um ato de intervenção direta na sua própria natureza, quer dizer, nos procedimentos e critérios que o definem enquanto tal. $\mathrm{O}$ que $\mathrm{o}$ documento legislativo que analisámos supra mostra, ${ }^{41}$ ao nível da política de ensino, é também uma determinada conceção de exercício do poder político. O conceito de "verdade nacional", explicitado como "verdade que convém à Nação" (ao Estado), definido operatoriamente segundo um critério político-ideológico, torna compreensível a atitude geral de desvalorização da informação e do conhecimento, da ciência, do saber (incluindo os seus procedimentos intelectuais, processuais e metodológicos).

A partir do momento em que se considera não haver um critério de racionalidade metodológica ou interpretativa acima das paixões e dos interesses dos homens ("tal historiador, tal atitude") ou que, simplesmente, se eliminam as condições de livre discussão que tornam possível o confronto de ideias e o juízo crítico, a história pode tornar-se mera narrativa edificante e teleológica, em função de interesses definidos segundo critérios extrínsecos ao seu corpus teórico e metodológico e à comunidade de investigadores.

${ }^{39}$ Ibid.

${ }^{40}$ Comentário de Ferry a Hannah Arendt, a propósito da crítica de Junger Habermas a Hannah Arendt. Cf. Jean-Marc Ferry, Habermas, L'éthique de la communication. Paris: PUF, 1987, p. 81.

${ }^{41}$ Decreto n. $^{\circ} 21$ 103, de 15 de abril de 1932. 
A "verdade nacional" é a verdade dos e para os portugueses, a "verdade portuguesa", no dizer de Eduardo Lourenço, ${ }^{42}$ definida em relação ao superior critério da portugalidade ou da lusitanidade e aplicada ao ensino e à educação. Referimo-nos a uma verdade cujo critério não é empírico, racional ou científico. É um critério político-estatal, que podemos considerar prático e legitimado pelo facto de estar assente em princípios religiosos e morais considerados como superior fundamento dos valores políticos. Todas as disciplinas escolares cujos conteúdos de ensino se liguem de modo mais próximo aos aspetos formadores do ensino sofrerão a pressão deste critério. O conceito de "verdade nacional", ainda que utilizado a propósito do ensino da história, é tomado por nós de modo exemplar.

A Escola corre o risco de se fragilizar enquanto lugar de aquisição, transmissão e aprendizagem de competências intelectuais. Este é o ponto fulcral a partir do qual podem ser colocados os problemas relativos à relação entre instrução e educação. A questão primeira é, assim, uma questão que envolve o saber e o seu significado, sob o ponto de vista filosófico, epistemológico, pedagógico, didático, político e humano. O que é que pode ser considerado como saber? Segundo que critérios se determina o ensinável no espaço da escola? Como determinar as competências a desenvolver na escola? Que intervenientes são legítimos na definição dos princípios educativos, na organização do sistema de ensino, na organização dos currículos e dos programas? A quem deve ser atribuída responsabilidade para gerir a conflitualidade de diversos interesses e definir as opções educativas, curriculares, programáticas?

A instituição escolar, de lugar de ensino, de transmissão de um património cognitivo, de aprendizagem de competências intelectuais, passa a ser, prioritariamente, um espaço educativo e político-ideológico de transmissão de determinados valores, ideias e crenças tendentes a perpetuar uma mentalidade comum, diminuindo as possibilidades de intervenção individual e crítica.

42 Eduardo Lourenço refere-se à “fabricação sistemática e cara de uma lusitanidade exemplar, cobrindo o presente e o passado escolhido em função da sua mitologia arcaica e reacionária que aos poucos substituiu a imagem mais ou menos adaptada ao País real dos começos do Estado Novo por uma ficção ideológica, sociológica e cultural mais irrealista ainda que a proposta pela ideologia republicana, por ser ficção oficial, imagem sem controlo nem contradição possivel de um país sem problemas, oásis da paz, exemplo das nações, arquétipo da situação ideal que conciliava o capital e o trabalho, a ordem e a autoridade com um desenvolvimento harmonioso da sociedade. Esse otimismo de encomenda teve nas famigeradas 'notas do dia' o seu evangelho radiofónico. Não vivíamos num país real mas numa 'Disneyland' qualquer, sem escândalos, nem suicídios nem verdadeiros problemas. O sistema chegou a uma tal perfeição na matéria que não parecia possível contrapor uma outra imagem de nós mesmos àquela que o regímen tão impune mas tão habilmente propunha sem que essa imagem-outra (não apenas ideológica, mas cultural) aparecesse como uma sacrílega contestação da verdade portuguesa por ele restituída à sua essência e esplendor". Eduardo Lourenço, O Labirinto da Saudade, Psicanálise Mitica do Destino Português. Lisboa: D. Quixote, 1978, p. 31. 
A sujeição do ensino a finalidades educativas pode, sob determinadas circunstâncias, ser também considerada uma forma de utilitarismo. A partir do momento em que os valores intelectuais associados ao ensino são sujeitos a um processo de desvalorização, submetidos a critérios de utilidade prática, no duplo sentido do termo, técnico e moral, a escola periga como lugar de formação e de desenvolvimento de competências intelectuais e cognitivas. É precisamente para esse risco que Vieira de Almeida aponta, quando, no âmbito de uma análise crítica ao ensino, neste caso da história, no ano de 1910 , afirma:

Desconhecer o valor da teoria, a sua influência como principal diretriz de todo o ensino, mesmo do técnico, é desconhecer o mais fundamental da educação e da instrução. É desconhecer o valor da ciência. ${ }^{43}$

Vieira de Almeida coloca-se no cerne da questão, apontando aquilo que, para nós, é o ponto de partida das posições sobre o ensino e a educação. Mesmo que não possamos obter uma só resposta para a pergunta, "Em que consistem o saber e a ciência?", são o saber e a ciência que devem permanecer como a referência e o horizonte teórico para os problemas referentes ao ensino, à educação e à escola. É em referência ao saber e à ciência, ao pensamento racional, filosófico e científico, tal como este se tem vindo a construir no Ocidente desde o século VI a.C., que o Ensino e a Escola, qualquer que seja o seu grau, se legitimam.

\section{A disciplina de Filosofia e a "orientação dos espíritos"}

No ensino da Filosofia durante os períodos da Ditadura Nacional e do Estado Novo a formação intelectual e moral assume particular importância, mas não há sinais de nacionalismo nos programas. Na Reforma liceal de 1936, num curso liceal de sete anos, distribuídos por três ciclos de estudos, encontramos a determinação de um livro único na disciplina de História, no $2 .^{\circ}$ ciclo (três anos), de educação moral e cívica, nos $1 .^{\circ}$ e $2 .^{\circ}$ ciclos (seis anos), e na de filosofia, no $3 .^{\circ}$ ciclo/7. ${ }^{\circ}$ ano (um ano). No entanto, na proposta original, posta à discussão na Assembleia Nacional, a disciplina de filosofia não estava incluída como devendo estar sujeita à determinação do livro único, o que não deve ser considerado um lapso ou esquecimento. Foi a proposta da deputada Maria

${ }^{43}$ Vieira de Almeida, Tese para o $4 .^{\circ}$ ano do Curso Superior de Letras, intitulada "História (significado e função)", apresentada em 1910. Obra Filosáfica, vol. I. Lisboa: Fundação Calouste Gulbenkian, 1986, p. 53. 
Guardiola ${ }^{44}$ para que também a disciplina de filosofia fosse contemplada com a obrigatoriedade do livro único que, sendo aprovada, levou à alteração da proposta de lei. No seu discurso, Maria Guardiola, depois de apresentar o conteúdo da proposta de lei em discussão, acrescenta:

Mas quero chamar a atenção de V. Ex..as para a vantagem que haveria se ele se adotasse também no ensino da filosofia.

Para a orientação dos espíritos é tão importante a existência de um só livro de filosofia como a de um só livro de história ou de educação moral e cívica. ${ }^{45}$

A questão fundamental da educação é colocada a nível da "orientação dos espíritos" em que a disciplina de filosofia prestará igualmente importante contributo.

O facto de a sujeição ao livro único não se ter colocado originalmente ao legislador no que se refere à disciplina de filosofia e de, apenas posteriormente o saber filosófico ter vindo a integrar com a história e a educação moral e cívica, o conjunto das matérias de ensino submetidas a um livro único, pode significar que alguma coisa se passa com os conteúdos da disciplina que deve merecer cuidado na sua seleção e ensino mas não do mesmo modo nem sob o mesmo ângulo da aprendizagem das primeiras letras ou da História ou com o mesmo grau de evidência. Quer a aprendizagem da leitura quer a da História (particularmente a da História Pátria) têm consequências na estruturação intelectual e afetiva do estudante que a filosofia não tem. Os conteúdos de ensino e os modelos eventualmente veiculados nas primeiras aprendizagens produzem um efeito na formação da personalidade intelectual, afetiva, moral, (para usar os termos da legislação) que não terá paralelo nas aprendizagens posteriores. Há um efeito de pregnância e de interiorização de comportamentos e valores que só a plasticidade da infầncia permite. No caso do Ensino Liceal, as grandes finalidades do ensino (o desenvolvimento do espírito nacionalista, o desenvolvimento do espírito corporativo, o culto da Pátria e do Império), são mais facilmente traduzidos em finalidades e objetivos na disciplina de história, com conteúdos e orientação que facilmente as corporizam, do que propriamente no ensino e aprendizagem da filosofia. A determinação do livro único, a nível da aprendizagem da leitura no ensino primário e da história, visa garantir que os conteúdos e a orientação de ensino

\footnotetext{
${ }^{44}$ Apresentada a propósito da discussão da proposta de lei n. ${ }^{\circ} 83$ sobre a reforma do Ministério da Instrução. Cf. Intervenção da deputada Maria Guardiola na sessão n. ${ }^{\circ} 70$ da Assembleia Nacional, a 6 de fevereiro de 1936, no âmbito da discussão da proposta de lei $n .^{\circ} 83$, sobre a reforma do Ministério da Instrução. Diário das Sessões, $\mathrm{n} .{ }^{\circ} 74$, de 7 de fevereiro de 1936.

${ }^{45}$ Ibid.
} 
contribuam positiva e ativamente para a interiorização de modelos comportamentais, de crenças e de valores cognitivos, estéticos, morais e religiosos de acordo com o ideal político de "bom português".

O caso da filosofia parece-nos mais complexo, principalmente por ser uma disciplina terminal do Ensino Secundário e por não contribuir, em sentido estrito, para uma das finalidades mais importantes do ensino: o propósito nacionalista. Os programas oficiais da disciplina desse ano de 1936 não contêm qualquer tema ou rubrica que verse diretamente sobre filosofia portuguesa ou em Portugal nem indiciam qualquer perspetiva de ensino nacionalista. Os manuais de estudo - que fogem frequentemente aos programas - também não manifestam tendências significativas nesse sentido.

O facto de ser uma disciplina terminal de estudos situa a sua intervenção principalmente a nível intelectual. O importante, no caso da disciplina de filosofia, é garantir que os seus conteúdos e orientação se coadunem com a ação educativa em curso. A idade da adolescência é considerada particularmente permeável às ideias e é a esse nível que a filosofia intervém, dominando e orientando no sentido da formação do pensamento consciente sob o ponto de vista intelectual e doutrinário e sob o ponto de vista de formação moral e política, garantindo o controlo sobre as ideias que se possam revelar perigosas. Isso exige que se assegure uma correta orientação no ensino da filosofia, de modo a contribuir para as finalidades formativas, morais e político-ideológicas do ensino. O seu lugar no plano de estudos e o seu estatuto curricular de disciplina de coroamento são acompanhados de uma conceção de filosofia como síntese e fundamentação dos saberes. A metafísica deverá fornecer o conjunto de ideias unificadoras que conferirão consistência ao conhecimento (quer objetivamente considerado, quer subjetivamente) e a moral contribuirá, não só para a formação do carácter, mas para a formação da consciência valorativa e para dar consistência, no plano racional das ideias e da doutrina, ao que até então era fundamentalmente uma prática e um conjunto de vivências. O tema "palpitante" 46 da moral é lecionado segundo uma perspetiva escolástica, incluindo a moral individual, económica e política ${ }^{47} \mathrm{~A}$ moral cristã é

${ }^{46}$ Usamos livremente o adjetivo constante no Parecer de A. A. Pires de Lima a um manual de Eugénio Aresta ( $c f$. Parecer da 3. Secção da Junta Nacional de Educação, assinado pelo relator, António Augusto Pires de Lima, datado de 16 de maio de 1940. Arquivo Histórico do Ministério da Educação, 15/2297).

${ }^{47}$ Cf. v.g. Compêndio de Jolivet, Cours de Philosophie (1937), pp. 351-377 (aprovado como livro único, por decisão ministerial, entre 1937 e 1940 e aprovado oficialmente mediante concurso em 1940); ou Compêndio de Eugénio Aresta, Noções de Filosofia. Porto: Editorial Marânus, 1940, pp. 518-602. 
explicitamente referenciada como conteúdo específico de ensino, pela primeira vez, nos programas de 1934 e 1935, está omissa em 1936, e reaparece a partir de 1948, o corporativismo e a doutrina social da Igreja constam normalmente na moral aplicada ou prática. $O$ ensino da Filosofia integra-se, assim, numa "educação espiritualista e cristã" ${ }^{48} \mathrm{e}$, sob este aspeto, presta um importante contributo. Parece ter sido esta importância que Maria Guardiola teria visto, ao mesmo tempo que o perigo que representaria deixá-lo fora de controlo. Foi o bastante para justificar a sua proposta de livro único para a disciplina de filosofia e a sua aceitação. O discurso da deputada na Câmara Corporativa sobre as finalidades últimas da educação é esclarecedor:

Formar homens e portugueses no mais alevantado e nobre sentido destas palavras, promover a unidade moral da Nação, o aperfeiçoamento dos costumes e a disciplina social, fazer ressurgir, em suma, a civilização cristã, que atravessa perene e intacta as fases da história portuguesa, colhendo delas ensinamentos para o futuro, é função da escola, que, por ser nacionalista nos seus fins, deverá sê-lo também nos seus meios e nos seus agentes. ${ }^{49}$

No entanto, não havia sinais preocupantes no campo da produção filosófica de ensino que justificassem grande apreensão. A tradição espiritualista de ensino da filosofia constituía um forte sustentáculo para as orientações de ensino vigentes ou que facilmente se adivinhavam. Nos programas de 1934 e de 1935, diz-se: "Mais do que em qualquer disciplina a filosofia deve ser mais formativa do que informativa". Os compêndios repetem frequentemente esta ideia tal como os relatórios de professores. Embora esta formulação não volte a aparecer ela ficará como marca da representação escolar da disciplina.

Os conteúdos programáticos enfatizam a moral culminando com a teodiceia (a partir de 1948) e os compêndios assumem uma orientação espiritualista de acento tomista ou cristão. Sem acento nacionalista nos conteúdos de ensino, cremos que, mais do que qualquer outra disciplina, é a de filosofia que se pode ligar de forma direta aos valores transcendentes e espirituais que fundam a nacionalidade. Devem ser banidos os "erros positivistas e raciona-

\footnotetext{
48 "Todos os esforços para o fortalecimento simultâneo daqueles elementos fundamentais da civilização [familia, fé, autoridade, firmeza e continuidade governativas, respeito da hierarquia e cultura literária e científica] serão inúteis, se abandonarmos a mocidade escolar à ação dispersiva e anárquica de orientações contraditórias e de interpretações informadas por um subjetivismo caprichoso; se não tivermos a coragem de lhe dar uma educação espiritualista e cristã [...]". Câmara Corporativa, Parecer sobre a proposta de lei n. $^{\circ} 83$, Diário das Sessões, $\mathrm{n}^{\circ}{ }^{\circ} 74$, de 5 de fevereiro de 1936. Disponível em: http://debates.parlamento.pt/r2/dan/ Imp_Img_dan.asp. Consulta a 27.05.2005.

${ }^{49}$ Ibid. 
listas", expressão que retiramos de José Bonifácio Ribeiro e José da Silva, autores de um dos manuais com maior expressão no ensino da filosofia no Estado Novo. ${ }^{50}$ No âmbito dos erros positivistas, encontramos certamente as críticas à metafísica e a queda no materialismo; nos racionalistas uma valorização da razão que, no limite, conduz ao ceticismo relativamente à metafísica e aos valores transcendentes que fundam a Moral. Podemos considerar que o uso da razão e das suas possibilidades críticas, sem o enquadramento teórico ou vivencial da Fé, significa uma ousadia, uma manifestação de orgulho e, pelas consequências sociais que pode acarretar, um perigo.

A metafisica, ausente dos programas da disciplina desde 1905 até 1929, foi reaparecendo paulatinamente até à Reforma de 1947/48, em que surge a fechar o programa. A rubrica da "moral cristã" apareceu pela primeira vez nos programas de 1934 e 1935, deixa de aparecer em 1936, reaparece em 1948 e manter-se-á na reformulação de 1954. No geral, os programas de filosofia no Estado Novo (1934, 1935, 1936, 1948, 1954) assumirão um certo ecletismo, no sentido de apresentação e conciliação de várias perspetivas filosóficas, sob um fundo espiritualista e cristão, valorizando a moral, a metafísica e a teodiceia (a fechar os programas de 1948 e de 1954).

O ensino da filosofia pode não responder ao desiderato do nacionalismo, em sentido estrito, bem representado no português durante o $1 .^{\circ}$ ciclo, que integra o ensino da história em forma de narrativas, ou no da história exaltando a Nação, os feitos e carácter dos portugueses, mas responde ao projeto mais amplo de "ressurgimento", alargamento e consolidação da civilização cristã.

Entretanto, o campo dito "formativo" vai-se prestando a todos os equívocos ao mesmo tempo que a formação proporcionada pela aprendizagem da filosofia é aproximada da formação proporcionada pela disciplina de organização política e administrativa da nação, pelas sessões de educação moral e cívica e, a partir de 1948, pelas de religião e moral (que se alarga ao 3. ${ }^{\circ}$ ciclo). Os professores de filosofia também lecionam organização política e administrativa da nação, alguns dos autores dos compêndios de educação moral e cívica são também autores dos compêndios de filosofia, o programa de ensino fecha com a teodiceia, o Deus que a filosofia pensa demonstrar tem o

${ }^{50} \mathrm{Cf}$. Documento enviado por José Bonifácio Ribeiro e José da Silva à Direção Geral do Ensino Liceal, recebido em 19 de maio de 1939 (Arquivo Histórico do Ministério da Educação, 15/1835). O conteúdo deste documento irá integrar o "Preâmbulo" da $1 .^{2}$ edição do Comcôndio destes autores (cf. José Bonifácio Ribeiro e José da Silva, Compêndio de Filosofia Marânus, 19qu, Liș̣oa: Livraria Portugália, 1940). 
mesmo rosto do Deus cristão a quem se presta culto. Como encontramos dito pelos manualistas mais reconhecidos:

Entramos depois na moral com a sua definição deduzida duma consideração que resume toda a moral católica e é essencial ao aluno para bem perceber o que se diz acerca de cada alínea do programa nesta parte. Supomos no aluno já muitos conhecimentos morais da cadeira de educação moral e cívica e esta é a razão por que desenvolvemos apenas as alíneas do programa, revestindo-as do que se requer para a sua perfeita compreensão. ${ }^{51}$

O objetivo de "formar" parece permitir o que, de um ponto de vista epistémico, ou mesmo educativo, não tem justificação: a mistura dos campos da filosofia, da religião e da política e, consequentemente, um uso ambíguo e equívoco dos seus conceitos.

As condições favoráveis para um ensino doutrinário da filosofia, orientado política e ideologicamente, fazem com que a filosofia possa ser considerada vítima das circunstâncias políticas e, especificamente, da política escolar e educativa, que dificultaram tanto o seu desenvolvimento no espaço universitário, como a sua afirmação escolar. Cava-se um fosso entre uma imagem escolar prestigiada, visível no seu estatuto curricular, ${ }^{52}$ e uma imagem escolar progressivamente desacreditada a que conduziram a manutenção do programa desde 1948 (apesar de uma remodelação em 1954) e as limitações dos compêndios de ensino aprovados.

Um movimento de renovação no ensino, cujo início sinalizamos com a primeira edição do Pequeno Manual de Filosofia de V. Magalhães Vilhena, em 1942, ${ }^{33}$ levado a cabo na prática docente de um modo mais ou menos clandestino, assinala o conflito entre duas visões da filosofia e do seu ensino: a visão oficial que entronca nas raízes do ensino aristotélico-tomista de forte tradição em Portugal e uma outra que recolhe de António Sérgio e de Vieira de Almeida a sua intencionalidade pedagógica e a sua perspetiva racionalista e crítica.

Em 1948, no mesmo ano em que se publicam novos programas e em que se acentua uma linha oficial de educação e ensino cristã e nacionalista, é publicada a primeira edição e o primeiro volume da Breve Antologia Filosó-

${ }^{51}$ Ibid.

${ }^{52}$ A partir da Reforma Liceal de 1947-1948 é disciplina obrigatória durante os dois anos do Curso Complementar dos Liceus, para todos os alunos, dos cursos de Letras e de Ciências, com quatro horas semanais.

${ }^{53}$ Vasco de Magalhães Vilhena, Pequeno Manual de Filosofia: de harmonia com os programas aprovados para o sétimo ano dos liceus e admissão à universidade. Lisboa: Livraria Sá da Costa, 1942. 
fica, de Joel Serrão e Jorge de Macedo, "preciosa Antologia", como a apelida Eduardo Lourenço, ${ }^{54}$ de orientação filosófica e didática diferente da do programa em vigor e que fará tradição no ensino. A partir de 1948, a par da progressiva intensificação dos mecanismos de controlo sobre a atividade docente, da imposição do livro único em 1950, começam a ser publicados diversos volumes e edições de antologias de textos filosóficos, por Joel Serrão e Jorge de Macedo e por Joel Serrão e Rui Grácio, que prosseguiram até à década de setenta. Estas antologias supõem uma visão do ensino filosófico diferente do postulado nos programas oficiais e fazem o seu percurso escolar à margem dos compêndios de ensino aprovados.

O facto de termos tido conhecimento de duas perspetivas de ensino da disciplina de Filosofia através de uma proposta precisa de programa, em 1918, de Leonardo Coimbra, e uma proposta mais genérica, em 1934, de António Sérgio, sob orientações filosóficas e didáticas diversas das que acabaram por ser aprovadas; a edição de manuais que não se referem ao papel formativo moral da disciplina, que não enfatizam a moral ou a metafísica no desenvolvimento dos seus conteúdos, a publicação de Antologias de textos a partir de 1948 , tudo isso mostra como um certo consenso em torno da ideia de que a disciplina de filosofia tem sobretudo uma função educativa interpretada como formação moral e ideológica foi também resultado de uma construção paralela à da ideia do predomínio do educativo sobre o instrutivo.

O enfraquecimento de um espaço público de comunicação ao longo do Estado Novo, a conotação do professor como sendo meramente um executor de programas e a sua funcionalização no espaço da escola, a ausência de possibilidade de escolha dos manuais de ensino são fatores importantes para que o saber e o conhecimento no espaço escolar se tenham tendencialmente reduzido a formas didáticas rotineiras de transmissão e de reprodução. $O$ desinvestimento na investigação, que marcou o período do Estado Novo, e a existência da Censura sobre todo tipo de publicações impedem também o desenvolvimento institucional da reflexão científico-pedagógica ou o estabelecimento de canais de comunicação entre a investigação no quadro do ensino universitário e a transmissão do saber a nível liceal, para além da que era contemplada na formação dos professores. Estes fatores limitavam a edição de obras e a margem de ação individual, mas não eram absolutamente impeditivos.

A dinâmica da ação, que inclui formas polimorfas de resistência individual, consegue, por vezes, ultrapassar normativos legais mostrando que nem sempre a lei e o poder coincidem.

${ }^{54}$ Cf. Eduardo Lourenço, Labirinto da Saudade, ed. cit., p. 178. 


\begin{abstract}
This article puts forward the following thesis: the legitimation of school subjects stems from an acknowledged epistemic field, from a science in its broadest sense. The more school subjects deviate from the science from which they originate the more they become weaken and disfigured. A focus on the Estado Novo period in Portugal allows for a particular understanding and emphasis placed on the context which legitimises Philosophy as a school subject in middle school. Thus, this article examines the avenues followed by Philosophy as a school subject in this particular historical period, accounting for and explaining the link between educational and instructional plans, the interference of ideology and education policy, and the transformation of school into an instrument of political, ideological education.
\end{abstract}

